\title{
Studying Microwave-Assisted Hydrolytic Degradation of Colchicine using RP-Chromatographic Methods: In Silico ADME/Tox Profile and Molecular Docking
}

nada abdelwahab ( $\square$ nadasayed2003@yahoo.com )

Beni Suef University Faculty of Pharmacy

hossam mokhtar

Beni Suef University Faculty of Pharmacy

asmaa aboulmaged

Nahda University

\section{Research article}

Keywords: Colchicine, microwave, ADME/Tox, Molecular docking, RP-chromatography

Posted Date: October 31st, 2019

DOI: https://doi.org/10.21203/rs.2.16552/v1

License: (c) (1) This work is licensed under a Creative Commons Attribution 4.0 International License. Read Full License 


\section{Abstract}

Colchicine, is a natural amide containing anti-gout treatment with versatile applications. Microwave assisted hydrolytic degradation is a newly alternative method thought to be more promising than traditional procedures of heating. It is an ecofriendly method that has more reproducible results due to the control of parameters. From this point, carrying on hydrolytic degradation of colchicine was tested for the first time under acidic conditions with the aided of microwave. The drug was hydrolyzed with the formation of deacylated analogue. Isolation of the resulted degradate was carried out using flash chromatography, the isolated one was elucidated based on $1 \mathrm{H}$ NMR data. Moreover, the results of human pharmacokinetic predictions conducted from in silico data showed that colchicine had higher blood brain barrier (BBB), plasma protein binding, and oral absorption than its deacylated derivative. The study was also extended to forecast the binding of colchicine and its degradate to the target protein. Furthermore, two stability indicating chromatographic methods were developed for quantification of the drug and its degradation product with high sensitivity. The first method was RP-TLC densitometric method that based on using a solvent mixture of water: methanol: diethylamine (70: 30: 15, by volume). The second one was RP-HPLC at which a mixture of water (containing $0.02 \%$ diethyl amine): methanol: acetonitrile (50: $20: 30$, by volume) was the used mobile phase. Validation parameters were calculated according to $\mathrm{ICH}$ recommendations and all were within the acceptable limits. These methods were used for determination of colchicine in its available tablets. They are the first developed stability indicating methods for analysis of colchicine and its degradation product.

\section{Background}

Colchicine is an alkaloid found in the seeds and bulb of colchicum that can be used as human and veterinary medicine. It is a powerful anti-inflammatory and anti-gout remedy, additionally, it is considered to be the sole treatment for Familial Mediterranean Fever (FMF) [1, 2]. Furthermore, it is used to treat certain dermatological conditions like leukocytoclasticvasculitis, sweet syndrome, and psoriasis [3] and is also recommended during primary biliary cirrhosis and breast cancer $[1,4]$. On the other hand, colchicine is reported to have low therapeutic index with narrow therapeutic effective concentration range, which makes its in vitro and in vivo analysis necessary to monitor its concentration [5].

Refereeing to the literature in hand, colchicine was determined in different matrices by various analytical methods like potentiometric [6] spectrophotometric [6, 7] and electrochemical methods of analysis [5, 8- 12]. In the same way, different chromatographic methods were also published for analysis of the studied drug including TLC-densitometry [13- 16], RP-HPLC [14, 17- 23], LC-MS [24, 25], and GC-MS methods [26].

Despite the fact that colchicine is a terminal amide containing drug which is susceptible to hydrolytic degradation with the production of the deacylated colchicine, none of the published methods studied the hydrolytic degradation of this drug. Stability study forms an essential part of the registration of a new drug product or substance which ensures the compliance of the newly discovered drug with the international regulations. It is also imperative to reflect the effect of various environmental conditions (like temperature, humidity, and light) on the quality of the drug, to ensure its safety and efficacy regardless the place in the world it will be shipped, and to identify potential degradation products [27-29]. Microwave heating assisted degradation is a 'cold' in-situ process at which heating takes place only when the molecule or the solution of interest absorbs microwave energy. It is used as an alternative tool to the traditional forced degradation method which minimizes the waste chemicals and hence reduces the hazardous environmental effect. Similarly, it reduces dramatically the time required for generation of the degradation 
products without the production of intermediates, increases product yield, and enhances the purity of the resulted product. Recently, it is widely used to study the forced degradation of several pharmaceuticals [30- 32].

Flash chromatography is a fast and economic approach substitution to the elderly used preparative column chromatography. It is widely used for isolation and purification of different molecules in highly pure form which is essential for performing microanalysis like MS and NMR analyses [33].

The pharmacokinetic profile of a drug molecule relies on ADME/Tox properties of a compound that deals with its absorption, distribution, metabolism, excretion, and toxicity throughout the human body. The vital goal of in silico ADME/Tox is to predict behavior of compounds in the whole body by collecting all kinetic processes in one global model. Prediction of molecule ADME/Tox in the early stages of drug development process are widely recognized. Fast evaluation of ADME/Tox properties will save both time and expense. Therefore, a large number of in-silico ADME/Tox soft wares have been recently used [34]. Molecular modeling, reveals the best fit orientation of a ligand that binds to a certain protein of interest. It affords useful information about the interaction and the binding orientation between the candidates and their protein targets [35].

Owing to the pharmaceutical importance of colchicine and lacking of methods published for studying its stability, the work in this manuscript aimed to study the hydrolytic degradation of colchicine using microwave aided heating through developing of two selective and sensitive chromatographic methods depending on using reversed stationary phases. Furthermore, isolation of the resulted degradate in highly pure form was done by using flash chromatography and then its structure was elucidated by ${ }^{1} \mathrm{H}-\mathrm{NMR}$ analysis. Likewise, the in silco data was used for the first time to expect ADME/Tox profile of the drug as well as its degradation product which is very important for expecting the toxicity resulted from degradation of dosage forms containing colchicine.

Also, molecular docking was used to study the interaction of the drug and the degradate separately with the target protein. This work is the first developed stability indicating one that can be easily applied in QC laboratories.

\section{Experimental}

\section{1. Equipment}

3. 1. 1. TLC-densitometerwas used for the developed RP-TLC densitometric method. It consisted of a CAMAG Linomat 5 autosampler (Switzerland) and CAMAG microsyringe (100 $\mu \mathrm{L})$ (Switzerland). UV scanning was carried out using 3S/N 130319 TLC Densitometric Scanner and the software used was WINCATS software (CAMAG, Muttens, Switzerland). The instrumental parameters was adjusted as follow: scanning mode was the reflectance-absorbance mode, scanning speed was $20 \mathrm{~mm} / \mathrm{s}$, the slite dimensions were $6 \times 0.3 \mu \mathrm{m}$, and deuterium lamp was the source of radiation. TLC silica gel 60 RP-18 F254S aluminum plates $(20 \times 10 \mathrm{~cm})$ were the used stationary phase with $5 \mu \mathrm{m}$ particle size and $200 \mu \mathrm{m}$ thickness (Merck, Germany). For TLC development, a glass chamber was used (Macherey-Nagel, Germany).

4. 1. 2. Regarding RP-HPLC method, the used instrument was Thermo Scientific Dionex UltiMate S 3000 UPLC system (Germany) with UltiMate 3000 quaternary pump (Germany). The detector was DAD-3000 Diode Array Detector (Germany) and the system was controlled by Chromeleon Chromatography Data System software. Samples was automatically applied using ACC-3000 autosampler (Germany) and the used column was XBridge ${ }^{\circledR}$ C18 (25 cm $\times 4.6 \mathrm{~mm}, 5 \mu \mathrm{m}$ particle size) (Massachusetts, USA).

5. 1. 3. Microwave-aided degradation experiments were done by using Synthesis reactor monowave 50 (Anton Paar GmbH, Austria) (Serial No. 82628529). 
6. 1. 4. Chromatographic separation was carried out using Reveleris ${ }^{\circledR} X 2$ Flash Chromatography System with multiple wavelengths UV detector, BÜCHI Labortechnik AG Meierseggstrasse 40 Postfach, Germany.

7. 1. 5. ${ }^{1} \boldsymbol{H}$ NMR spectra were recorded in $\delta$ scale given in ppm on a Bruker $400 \mathrm{MHz}$ spectrophotometer in DMSO$d_{6}$, Switzerland.

8. 1. 6. FT-IR spectra were recorded on a Shimadzu IR 435 spectrophotometer, Japan.

9. Software

10. 2. 1. In silico ADME properties was performed via Online PreADMET program and Molinspiration program [3638] depending on 2D structural models, drawn in ChemBioDraw Ultra version 11.0 software (Cambridge Software).

11. 2. 2. For molecular descriptor analysis, the molecular properties of the drug and its degradate were calculated using "Calculate" module of MOE of (Chemical Computing Group software, Canada). These descriptors include MW, number of Hydrogen-bond acceptors (a_acc), number of Hydrogen-bond donors (a_don), an octanol/water partition coefficient $(\log P)$, number of rotatable bonds (B_rotN), and polar surface area (ASA_P).

12. 2. 3. Toxicity profiling were conducted using PreADMET program software version 2.0 . Toxicity profile involves screening for Acute algae toxicity, AMES (activity in the salmonella/mammalian microsome mutagenicity) carcinogenicity (mouse and rat), Acute daphina toxicity, in vitro hERG inhibition, and acute fish toxicity.

13. 2. 4. Molecular docking for the compounds on the target protein were carried out using Molecular Operating Environment (MOE 2019, Chemical Computing Group Inc, Montreal, Quebec, Canada, http://www.chemcomp.com) software [39]. A crystal structure of tubulin, (PDB : 4LZR) was obtained at $1.85 \AA$ and downloaded from the protein data bank (PDB) (http:// www.rcsb.org/pdb/home/home.do, access on 14 June 2019 11AM).

\section{3. Samples and chemicals}

15. 3.1. Colchicine was given as a gift from El Kahira Pharm. \& Chem. Ind. Co. (Cairo, Egypt) with purity of $100.31 \pm$ 1.74 according to the reference method [1]. While colchicine ${ }^{\circledR}$ tablets (B. NO. 64719) were obtained from local market and were labeled to contain $500 \mu \mathrm{g}$ colchicine / tablet. This dosage form was manufactured by El Nasr Pharmaceutical Chemicals Co. "ADWIC".

16. 3. 2. The chemicals used were: concentrated $\mathrm{HCl}$, dichloromethane, and $\mathrm{NaHCO}_{3}$ (El Nasr Pharmaceutical Chemicals Co., Abu- Zabaal, Cairo, Egypt). Additionally, Acetonitrile, methanol (HPLC grade, SDS, France), and diethylamine (99\%) (Loba Chemie, Mumbai, India) were used. The water used was deionized water (SEDICO pharmaceuticals Co., Cairo, Egypt).

\section{4. Solutions}

Stock solutions of $1 \mathrm{mg} / \mathrm{mL}$ each of colchicine and the isolated degradate were separately prepared by dissolving accurately weighed $0.1 \mathrm{~g}$ of each in $100 \mathrm{~mL}$ methanol. Further dilutions were then carried out on the prepared stock solutions $(1 \mathrm{mg} / \mathrm{mL}$ ) by using the mobile phase mixture of water (containing $0.02 \%$ diethyl amine): methanol: acetonitrile (50: 20: 30, by volume) for RP-HPLC method to prepare their working solutions $(0.1 \mathrm{mg} / \mathrm{mL})$.

In order to prepare the solution of the tested tablets $(200 \mu \mathrm{g} / \mathrm{mL})$, the content of ten tablets were accurately weighed, grinded, and mixed well. A quantity equivalent to $2 \mathrm{mg}$ of colchicine was accurately transferred to 10-mL volumetric flask and then dissolved in $7 \mathrm{~mL}$ methanol, ultrasonicated for about $10 \mathrm{~min}$. The extracted tablets were then left to cool and the volume was finally adjusted with methanol. The prepared solution was then filtered and used to prepare different dilutions within the linearity range of each method either by using methanol (for RP-TLC densitometry) or by the mobile phase mixture (for RP-HPLC method). 


\section{5. Procedure}

\section{5. 1. Preparation of the degradation product}

$0.1 \mathrm{~g}$ of colchicine in $1 \mathrm{~mL}$ methanol and $2 \mathrm{~mL}$ of different concentrations of $\mathrm{HCl}(1 \mathrm{~N}$ and $2 \mathrm{~N})$ were subjected to microwave radiation for 2 minutes. Methanol was distilled off under vacuum using rotaevaporator and the formed precipitate was then dissolved in $3 \mathrm{~mL}$ distilled water and then neutralized by aqueous $\mathrm{NaHCO}_{3}$ till $\mathrm{pH}$ 7-7.5. The deacylated degradate was obtained by extraction with dichloromethane $(2 \times 10 \mathrm{~mL})$ and then further purification was carried out using flash chromatography.

\section{5. 2. Purification of the degradation product}

The resulted degradation product was subjected to purification using Reveleris ${ }^{\circledR}$ X2 Flash Chromatography system on C18 Column $(50 \mu \mathrm{m}, 12 \mathrm{~g})$ RP-silica. Isolation was carried out in gradient elution manner starting with $10 \%$ methanol in water (containing $0.02 \%$ diethyl amine): till reaching $100 \%$ methanol (containing $0.02 \%$ diethyl amine). The collected fractions were combined together, evaporated under vacuum using rotavaporator and then tested for purity using RP-TLC. The isolated degradate was then subjected to IR and ${ }^{1}$ HNMR analyses for structural elucidation.

\section{5. 3. Linearity and construction of calibration curves}

For RP-TLC densitometric method, linearity was achieved in the concentration ranges of 0.2- 4 and 0.1- $4 \mu \mathrm{g} / \mathrm{band}$ for colchicine and its degradate, respectively. Different concentrations of the drug and the degradate $(10-400 \mu \mathrm{g} /$ $\mathrm{mL}$ ) were separately prepared in $10 \mathrm{~mL}$ methanol from their respective stock solutions $(1 \mathrm{mg} / \mathrm{mL})$. Accurate $10 \mu \mathrm{L}$ of each sample was applied in triplicates as band to RP- TLC aluminum plates $(20 \times 10 \mathrm{~cm})$. The width of the band was adjusted to be $3 \mathrm{~mm}$ and the bands spaced by $8.9 \mathrm{~mm}$ from each other and by $10 \mathrm{~mm}$ from the base of the plate. The chromatographic development was carried out in a glass tank previously saturated for about 15 min with $50 \mathrm{~mL}$ of water: methanol: diethyl amine mixture (70: 30: 15, by volume). After development to a distance of about $90 \mathrm{~mm}$, the plates were air dried and then UV scanned at $254 \mathrm{~nm}$. The recorded response was the peak area which was then plotted against the corresponding concentration of each analyte to compute its regression equation.

For RP-HPLC method, different samples in the rage of $2-40 \mu \mathrm{g} / \mathrm{mL}$ were separately prepared in two sets of $10 \mathrm{~mL}$ calibrated flasks using their previously prepared working solutions $(0.1 \mathrm{mg} / \mathrm{mL})$. Dilutions were done by the mobile phase mixture of water (containing $0.02 \%$ diethyl amine): methanol: acetonitrile (50: 20 : 30 , by volume). $40 \mu \mathrm{L}$ of each flask was then injected in triplicates to HPLC system. The mobile phase used was pumped at $2 \mathrm{~mL} / \mathrm{min}$, the run time was adjusted at 4 min and UV scanning was performed to $254 \mathrm{~nm}$. Peaks area of the eluted analytes was recorded and used for plotting its corresponding calibration graph and computing the regression equation.

\section{5. 4. Analysis of marketed samples}

For RP-TLC densitometric method, accurate $7.5 \mu \mathrm{L}$ was applied to RP-TLC aluminum plates from the previously prepared tablets solution $(200 \mu \mathrm{g} / \mathrm{mL})(\mathrm{n}=6)$. Chromatographic conditions following during construction of calibration curves for RP-TLC densitometric method was then followed and the computed regression equation for colchicine was used to calculate its recovered conecentration.

For RP-HPLC method, a sample equivalent to $15 \mu \mathrm{g} / \mathrm{mL}$ colchicine were prepared in $10 \mathrm{~mL}$ mobile phase mixture from sample solution previously prepared $(200 \mu \mathrm{g} / \mathrm{mL})(\mathrm{n}=6) .40 \mu \mathrm{L}$ of each dilution was injected to HPLC system and then instructions under linearity were followed. Concentrations of the drug were then obtained by substitution in 
its corresponding regression equation. Moreover, standard addition technique for each method was performed on three different levels for both methods.

\section{5. 5. Molecular docking}

MOE software was used to protonate the crystal structure of tubulin [39]. The following parameters are adjusted to carry out the docking of colchicine and its degradate into the active site of tubulin. (1) The triangle matcher algorithm was selected to dock the targeted compounds to the active site; (2) London dG scoring was specified to rank the poses; (3) The Force field refinement was specified to release the poses, and (4) Affinity $\Delta G$ scoring was specified to classify the poses using the refinement step. Van der Waals, ionic, and hydrogenated interactions that were recognized between the protein and the ligand contribute in calculating the binding free energy score. After the docking process was completed, ligand interaction 2D \& 3D diagrams for each compound was created based on the analysis of the binding sites

\section{Results And Discussions}

Regarding to the recommendations of International Conference on Harmonization (ICH) [40], it is a must to study the drug degradation profile as well as to characterize the produced degradate and its expected toxic effect. Inclusive searching in the published methods for determination of colchicine, no stability indicating assay method has been reported for studying the hydrolytic degradation of colchicine and the toxicity of its hydrolytic degradation product which is essential to minimize the risk of toxicity due to degradation of drug substance or product [41, 42]. Additionally, performing the hydrolytic degradation under microwave controlled heating has advantages of significantly reducing time of degradation from several hours to few minutes, giving reproducible results, and almost pure degradation product. In this manuscript, the hydrolytic degradation of colchicine was studied for the first time by using two concentrations of $\mathrm{HCl}(1$ and $2 \mathrm{~N})$ under microwave controlled heating. The work was then protracted to isolate the resulted degradate in highly pure by using flash chromatography. Likewise, molecular modeling of the resulted degradate on the target protein was performed. The drug and its degradate were also quantified with high sensitivity even though their structural similarity through developing of two new chromatographic methods, RP-TLC densitometric and RP-HPLC methods.

\section{1. Degradation behavior of colchicine}

It was observed that the drug was sensitive for hydrolytic degradation and its degradation rate affected by concentration of $\mathrm{HCl}$ used. Upon degradation with $1 \mathrm{~N} \mathrm{HCl}$ for two minutes, $65 \%$ degradation was observed while 85 $\%$ degradation was resulted on using $2 \mathrm{~N} \mathrm{HCl}$ for the same time. After degradation, the produced degradate was isolated by extraction of the neutralized solution with methylene chloride (3X10 mL) and then purified with flash chromatography by using mixture of methanol: water (containing $0.02 \%$ diethyl amine) in gradient elution mode. Fractions was tested by RP-TLC densitometry and those containing the degradate in pure form were collected together, evaporated under vacuum till dryness. Structure elucidation of the degradate was then confirmed by IR and

${ }^{1} \mathrm{H}$ NMR analyses. ${ }^{1} \mathrm{H}$ NMR spectra revealed the disappearance of methyl group and $\mathrm{NH}$ proton and the appearance of $\mathrm{D}_{2} \mathrm{O}$ exchangeable signals at around $\delta 9.15 \mathrm{ppm}$ corresponding to $\mathrm{NH}_{2}$ protons. FT-IR spectra revealed the disappearance of amidic carbonyl group of colchicine with the presence of tropolone carbonyl group at $1769 \mathrm{~cm}^{-1}$ and forked signal of $\mathrm{NH}_{2}$ group around $3299-3276 \mathrm{~cm}^{-1}$. The pathways adopted for the degradation of colchicine is depicted in Fig. 1

\section{2. Methods development and optimization}




\section{2. 1. RP-TLC densitometric method}

Trials for TLC densitometric method began with using normal phase TLC plates using different developing systems, unfortunately none of the tested systems succeeded in elution of the produced degradate with symmetric non tailed peak. After that, RP- TLC plates were tested using different solvent mixtures such as water: methanol, water: acetone, methanol: ethylacetate, and water: acetonitrile. All these systems were tried in different ratios but the most acceptable separation between the drug and the degradate was resulted on using a mixture of water: methanol (70: $30, v / v)$ but with highly tailed peak for the degradate. Using methanol $\nabla 30 \%$, resulted in decreasing the resolution between the two components but decreasing its ratio increased the time required for chromatographic development dramatically. In a trial to enhance the shape and the symmetry of the peak of the degradate, different ratios of acetic acid (1- $5 \%, v / v)$ and diethyl amine (1- 20\%, v/v) were separately added to the solvent mixture. Diethyl amine was reported to act as silanol blocker as well as ion pair reagent [43], hence it was found that addition of $15 \%$ diethyl amine was necessary to elute the degradate from the stationery phase with nearly symmetric non tailed peak and hence the optimum chromatographic efficiency. The chosen developing system was water: methanol: diethyl amine (70: 30: 15, by volume). Moreover, UV scanning was tested at different wavelengths in order to achieve the highest sensitivity with low noise $(220,240,254$, and $350 \mathrm{~nm})$. Concerning the drug and its degradate, the chosen detection wavelength was $254 \mathrm{~nm}$. Effect of saturation of the chromatographic chamber with the mobile phase mixture on the efficiency of the separation was tested (15, 30, and $60 \mathrm{~min}$ ) where 15 min was sufficient as a saturation time. On using the optimum conditions, acceptable separation between colchicine and its deacylated analogue was observed and the resulted $R_{f}$ values were 0.6 and 0.7, respectively, Fig. 2.

\section{2. 2. RP-HPLC method}

Depending on the previous trials of the developed RP-TLC densitometric method, diethyl amine was necessary to elute the degradation product from reversed stationary phase with acceptable peak shape. Hence, HPLC experiments started on RP-C18 column with mixtures of water (containing $0.01 \%$ diethyl amine): methanol (from $40 \%-90 \%, \mathrm{v} / \mathrm{v}$ methanol). Acceptable separation was obtained on using $50 \%$ methanol but in all ratios, the peak of the degradate was tailed. Methanol was then substituted with acetonitrile which resulted in un-tailed peaks for both analytes but with nearly the same $t_{R}$ values. Increasing water ratio, extended the analysis time and decreased the symmetry of the peaks. Combined mixtures of water (containing $0.01 \%$ diethyl amine): methanol: acetonitrile with different ratios were tried to improve the separation efficiency. The optimum ratio was 50: 20: 30, by volume. Ratios of diethyl amine was then optimized by testing different ratios $(0.01-0.03 \%, \mathrm{v} / \mathrm{v})$ where $0.02 \%$ diethyl amine was sufficient for providing symmetric peaks with complete separation. The mobile phase flow rate was then tested to decrease the run time $(0.7-2 \mathrm{~mL} / \mathrm{min})$, maintaining the flow rate at $2 \mathrm{~mL} / \mathrm{min}$ resulted in a run time of 4 min without affecting the chromatographic resolution. Similarly, column temperature was optimized by testing several temperatures (25-40 $\left.{ }^{\circ} \mathrm{C}\right)$. Temperature had no significant effect on the separation performance and hence column temperature was kept constant at $25^{\circ} \mathrm{C}$. Different scanning wavelengths were tried $(220,240,254$, and $350 \mathrm{~nm})$ where the effluent was detected at $254 \mathrm{~nm}$ which gave the suitable sensitivity required for quantitation of the drug and its deacylated degradate. Finally, complete separation was got on using RP-C18 column and a mobile phase of water (containing 0.02\% diethyl amine): methanol: acetonitrile (50: 20: 30, by volume), flow rate $=2 \mathrm{~mL} / \mathrm{min}$, and UV detection at 254 $\mathrm{nm}$. $\mathrm{t}_{\mathrm{R}}$ values were 1.97 and $2.97 \mathrm{~min}$ for the degradate and the drug, respectively, Fig. 3.

\section{3. Validation of the developed methods}

Recommendations reported in $\mathrm{ICH}$ [44] guidelines for method validation was followed. 
Linearity of the proposed RP-TLC densitometric method was tested and was verified in the ranges of 0.2- 4 and 0.1$4 \mu \mathrm{g} /$ band for colchicine and the degradate, respectively using polynomial regression which resulted in lower LOD and LOQ values than linear regression. On the other hand, linearity of RP-HPLC method was ascertained in the range of $2-40 \mu \mathrm{g} / \mathrm{mL}$ for both analytes using linear regression (for colchicine) and polynomial regression (for the degradate). Parameters of the computed regression equations are given in Table 1, values of the resulted correlation coefficients revealed that the developed methods are linear within the tested ranges.

Besides, accuracy of these methods was tested by applying them to analyze different pure samples $(n=9)$ each of the drug and its degradate following the instructions of each method. Mean percentage recovery of each analyte was calculated and found to be 99.38 and 100.59\% (for RP-TLC densitometric method) and 99.92 and 100.01\% (for RP-HPLC method) for the drug and the degradate, respectively. All the results are near the acceptable value (100\%) ensuring accuracy of the two methods. Likewise, intraday and interday precision, represented as SD, were tested by analysis of different three concentrations of each compound either on the same day (for intraday precision) or on three consecutive days (for interday precision). Low SD values ( $\mathbb{2} \%$ ) were resulted confirming that the developed methods are precise, Table 1. Specificity of the methods was assured by the good separation of the parent drug and its deacylated analogue Figs. 2 and 3. Additionally, no interference from tablets additives were found on analysis of the available tablets dosage form which was proved from the results given in Table 2. Limits of detection (LOD) and quantitation ( $\mathrm{LOQ}$ ) were calculated using the slope method ( $\mathrm{LOD}=3.3 * \mathrm{SD} /$ slope, $\mathrm{LOQ}=10 * \mathrm{SD} /$ slope) where low values were resulted, Table 1 confirming that the methods possess the sensitivity required for detection of low concentrations of the resulted degradate. In addition, robustness of the method determined the ability of the method to resist small intended changes in parameters and it was expressed as \%RSD. Robustness was checked by changing amount of diethyl amine $( \pm 2 \%)$, methanol $( \pm 1 \%)$ [for RP-TLC densitometric method], mobile phase flow rate $( \pm 0.05 \mathrm{~mL} / \mathrm{min})$, and detection wavelength $( \pm 2 \mathrm{~nm})$ [for RP-HPLC method] and measuring the effect of these changes on values of $R_{f}$ (for RP-TLC densitometric method) or $t_{R}$ (for RP-HPLC method). All the obtained \%RSD values were within the acceptable limits ensuring that the methods did not affected by the studied changes, Table 1. Finally, system suitability testing parameters such as peak symmetry, capacity, selectivity, and resolution factors as well as number of theoretical plates and height equivalent to theoretical plates were calculated. All the calculated parameters ensured that the methods have good specificity and efficiency, Table 3.

After validation of the proposed chromatographic methods, they were successfully used to measure concentrations of colchicine in Colchicine ${ }^{\circledR}$ tablets and the recovered concentration of the active drug (105.38 and $107.16 \%$ for RP-TLC densitometric and RP-HPLC, respectively) ensured the validity of the method, Table 2. Standard addition technique was also done and the results obtained indicated that there was no interference from tablets excipients confirming accuracy of these methods, Table 2.

As well, statistical comparison between the results of the developed methods and the reference one [17] was carried out by using student's $t$ and $F$ test for variance and the results showed that the difference between the two methods and the reference one is not significant, Table 1.

\section{4. In silico molecular and ADME properties}

In most drug discovery projects sorting out the ADME/ Tox issues is the most challenging part of the project as pharmacokinetic (ADME) and pharmacodynamic (e.g., toxicological) properties (drug-likeness) are of great importance during pre-clinical evaluation to optimize a lead compound into a successful drug candidate, and to minimize attrition rates during clinical trials. Some active compounds pass through Blood-brain barrier (BBB), thus it is important in pharmaceutical sphere to study it. Forecasting human intestinal absorption (HIA \%) of drugs is 
considered the key physicochemical parameter for identifying potential drug candidate [45]. Another important consideration regarding the development of bioactive molecules as therapeutic agents is oral bioavailability. An effective in vitro model for the prediction of oral drug absorption is suggested to be Caco-2 cell model and MadinDarby canine kidney (MDCK) cell model. [46].

In the pharmaceutical fields, transdermal delivery of drugs become a crucial parameter and thus it is important to predict the skin permeability (SP) rate. In this study, the pharmacokinetic parameters namely; G protein-coupled receptors ligand (GPCR), kinase inhibition (KI), nuclear receptor ligand (NRL), ion channel modulation (ICM), protease inhibition (PI), and enzyme inhibition (EI) were important descriptors chosen to be calculated via Molinspiration software. These values indicate binding affinity of colchicine and its deacylated form to the mentioned receptors and enzymes. Table 4. From the results, colchicine showed relatively higher BBB value than its deacylated analogue and this is contributed to the hydrophilic nature of the amino group of the degradate. Additionally, colchicine showed higher plasma protein binding, oral drug absorption, G protein-coupled receptors ligand, ion channel modulation, kinase inhibition, and nuclear receptor ligand.

A drug-like molecule (DLM) possesses the physicochemical properties that might enable it to become a drug. Generally speaking, an orally available molecule that satisfies Lipinski's rule (Lipinski-compliant) and shows a balance between lipophilicity and hydrophilicity would qualify it to be a drug-like molecule [47].

An orally active compound should obey both Lipinski's and Veber's rules. As shown from Table 5, both compounds followed both Lipinski's and Veber's conditions.

Toxicity screening results of preADMET for colchicine and its deacylated product showed mutagenicity against AMES mutagenicity with positive TA100_NA stain and negative for the other strains used. Moreover, both compounds showed no potential rodent carcinogenicity except against rat. Also, hERG_inhibition is of low risk for both the drug and its degradate. Yet the degradate has a slight increase in the toxicity value against algae_at, daphnia_at, medaka_at \& minnow_at, Table 6. The results of in silico screening highlights the necessity to conduct lead optimization for colchicine containing pharmaceutical dosage forms to minimize its degradation to more toxic analogue.

\section{5. Molecular docking}

In this present work, the automated molecular docking was used to determine the orientation of colchicine and its deacylated analogue bound in the active site of the tubulin (PDB: 4LZR). In order to achieve different binding conformations, the structures of both the drug and its degradate as well as the enzyme were kept flexible and the best-docked complex obtained was recognized and analyzed in detail. Validation of molecular docking was carried out by extracting the native specific ligand of tubulin from the binding site and then redocked the conformation of the ligand to the binding site to guarantee the reliability and reproducibility of the docking procedure.

The docking of target molecules with tubulin reveals that they were exhibiting the bonding with two amino acids in the active site which is showed in Fig. 4. From the resulting docking procedures, it is clear that the compounds attached to the active binding site of the target enzyme. Colchicine showed high energy docking binding score (-13.87 kcal/mol) with hydrophobic binding interaction with lle146 amino acid, Fig. 4A. Additionally, the deacylated analogue showed relatively the same docking score $(-13.86 \mathrm{kcal} / \mathrm{mol})$ linked to the active site of tubulin through hydrogen bond interaction between amino group and ASN140, Fig. 4B. 


\section{Conclusion}

Forced degradation study of colchicine has been conducted with assistance of microwave which resulted in the formation of a product that was not reported before. The produced degradate was identified as deacylated colchicine by ${ }^{1} \mathrm{HNMR}$ and IR spectra. Quantitation of the drug and its deacylated analogue was achieved through developing of two chromatographic methods, RP-TLC densitometric and RP-HPLC methods. Analysis time required for the two methods was short and thus minimum amounts of hazardous solvents was needed. The study expanded knowledge space concerning ADME/Tox profile of the drug and the formed degradate. Additionally, this work demonstrated that the resulted degradate possess lower penetration to BBB and slightly higher algae_at, daphnia_at, medaka_at, and minnow_at values than the parent drug. Also, docking study revealed the ability of the degradate to bind in the same active site of the target tubulin.

\section{Declarations}

\section{Compliance with ethical standards}

Disclosure of potential conflicts of interest: Authors declare that they have no conflict of interest.

Research involving human participants and/ or animals: no human volunteers or animals were used in this work.

Funding: this work is self funded.

Ethics approval and consent to participate: not applicable.

Consent for publication: not applicable.

Authors' contributions: Nada S. Abdelwahab and Asmaa M. Aboul Magd contribute to the idea, practical analysis plan and carried out the practical analysis, shared writing the manuscript.

Hossam M. Hassan helped in isolation of the degradate and writing this part in manuscript

Acknowledgement: The authors express their appreciation and thanks to El Kahira Pharm. \& Chem. Ind. Co. (Cairo, Egypt) for supplying colchicine drug.

\section{References}

1-E. Niel, JM. Scherrmann, Colchicine today. Joint, bone, spine: Revue Du Rhumatisme, 2006, 73 (6): $672-678$.

2-L. Kuritzky, R. Panchal, Gout: nonsteroidal anti-inflammatory drugs and colchicine to prevent painful flares during early urate-lowering therapy. J. Pain Palliat Care Pharmacother., 2010, 24: 397-401.

3-Y. Adler, J. Finkelstein, A. Guindo et al., Colchicine treatment for recurrent pericarditis a decade of experience. Circulation, 1998, 97: 2183-2185.

4- B. Bhattacharyya, D. Panda, S. Gupta, M. Banerjee, Anti-mitotic activity of colchicine and the structural basis for its interaction with tubulin. Med. Res. Rev., 2008, 28: 155-183. 
5-D. A. R. Moreira, F. M. de Oliveira, D. M. Pimentel et al., Determination of colchicine in pharmaceutical formulations and urine by multiple-pulse amperometric detection in an FIA system using boron-doped diamond electrode, J. Brazilian Chem. Soc., 2018, 29 (9): 1796-1802.

6-“The British Pharmacopoeia” (2012) Her Majesty's stationary office. London: Electronic Version.

7-P. Arpna, V. Purnima, Development of UV spectrophotometric method for estimation of colchicine in phosphate buffer saline pH 6.4. Int. Res. J. Pharm., 2013, 3: 87- 89.

8-E. Aboul Kasim, Voltammetric behavior of the anti-inflammatory alkaloid colchicine at a glassy carbon electrode and hanging mercury electrode and its determination at PPB levels. Anal. Lett., 2002, 35: 1987- 2004.

9-H. Zhang, Electrochemistry and voltammetric determination of colchicine using an acetylene black-dihexadecyl hydrogen phosphate composite film modified glassy carbon electrode. Bio electrochemistry, 2006, 68: $197-201$.

10-E. Bodoki, R. R. L. Sandulescu, Method validation in quantitative electrochemical analysis of colchicine using glassy carbon electrode. Central European J. chem., 2007, 5: 766- 778.

11-F. Wang, J. Zhou, Y. Liu, S. Wu, G. Song, B. Ye, Electrochemical oxidation behavior of colchicine on a graphene oxide-nafion composite film modified glassy carbon electrode. Analyst, 2011, 136: 3943- 3949.

12-D. M. Stankovic, L. Svorc, J. F. M. L. Mariano, A. Ortner, K. Kalcher, Electrochemical determination of natural drug colchicine in pharmaceuticals and human serum sample and its interaction with DNA. Electroanalysis, 2017, 29: 2276- 2281.

13-E. Bodoki, R. Oprean, L. Viase, M. Tamas, R. Sandulescu, Fast determination of colchicine by TLC-densitmetry from pharmaceuticals and vegetal extracts. J. Pharm. Biomed. Anal., 2005, 37: 971- 977.

14-G. M. Hadad, J. M. Badr, K. El-Nahriry, H.A. Hassanean, Validated HPLC and HPTLC methods for simultaneous determination of colchicine and khellin in pharmaceutical formulations. J. Chromatogr. Sci., 2013, 51(3): $258-265$.

15-M. Fahim, S. Mhaveer, Y.T. Kamal, M. M. Hayat, A. Sayeed, A high performance thin layer chromatographic method for the estimation of colchicine in different formulations, J. Pharm. Bio. Sci., 2015, 7: 260-263.

16-I. A. Mohamed, M. A. Omar, S. M. Derayea, M. A. Hammad, A. A. Mohamed, Validated thin-layer chromatographic method for alternative and simultaneous determination of two anti-gout agents in their fixed dose combinations, Open Chem., 2018, 16: 496-510.

17-“The United States Pharmacopeia," (2012) National Formulary 35, United States Pharmacopeia Convention Inc., $30^{\text {th }}$ Ed.

18-V. F. Samanidou, G. A. Sarantis, I. N. Papadoyannis, Development and validation of a rapid HPLC method for the direct determination of colchicine in pharmaceuticals and biological fluids. J. Liq. Chromatogr. Relat. Technol., 2006, 29 (1): 1-13.

19-K. Nirmala, R. R. Ramesh, A novel method development for validation and detection of colchicine drug by RP-HPL, Rasayan J. Chem., 2012, 5: 106-111. 
20-G. G. Babu, High performance liquid chromatographic determination of colchicine in pharmaceutical formulations and biological fluids. Int. J. Pharm. Pharm. Sci., 2014, 6: 335- 337.

21-V. Maslarska, I. Pencheva, Determination of colchicine content in drug by RP-HPLC. Int. J. Adv. Pharm. Bio. Chem., 2014, 3: 116- 119.

22-I. M. Abdulbaqi, N. Khan, R. Abou Assi, A simple (HPLC-UV) method for the quantification of colchicine in bulk and ethosomal gel nano-formulation and its validation, Int. J. Pharm. Pharm. Sci., 2017, 9: 72-78.

23-S. A. Joshi, S. S. Jalalpure, A. A. Kempwade, M. Rao Peram, Development and validation of HPLC method to determine colchicine in pharmaceutical formulations and its application for analysis of solid lipid nanoparticles, Current Pharm. Anal., 2018, 14: 76-83.

24-E. Abe, AS. Lemaire-Hurtel, C. Duverneuil et al. A novel LC-ESI-MS-MS method for sensitive quantification of colchicine in human plasma: application to two case reports. J. Anal. Toxicol 2006, 30:210-5.

25-Y. Jiang, J. Wang, Y. Wang, H. Li, JP. Fawcett, J. Gu, Rapid and sensitive liquid chromatography-tandem mass spectrometry method for the quantitation of colchicine in human plasma. J. Chromatogr. B, 2007, 850:564-568.

26-C. V. Clevenger, T. F. August, L. M. Shaw, Colchicine poisoning: Report of a fatal case with body fluid analysis by GC/MS and histopathologic examination of postmortem tissues. J. Anal. Toxicol., 1991, 15(3):151-154.

27-N. S. Abdelwahab, N. F. Farid. Validated HPLC-DAD method for stability study of sulbutiamine HCl. RSC Adv., 2014, 4: 30523.

28-N. F. Farid , N. S. Abdelwahab, Stability-Indicating HPTLC method for studying stress degradation behavior of sulbutiamine HCl. J. Chromatogr. Sci., 2016, 54(4): 609- 617.

29-M. M. Abdelrahman, N. S. Abdelwahab, A. A. Taha, J. M. Boshra, Different sability indicating chromatographic methods for specific determination of paracetamol, dantrolene sodium, their toxic impurities, and degradation products. Biomed. Chromatogr., 2019, 20: e4598.

30-B. Prekodravac, M. Damm, CO. Kappe, Microwave-assisted forced degradation using high throughput microtiter platforms. J. Pharm. Biomed. Anal. 2011, 56:867-873.

31-P. Patel, P. Mehta, Microwave-assisted heating: innovative use in hydrolytic forced degradation of selected drugs. J. Microw. Power Electromagn. Energy, 2017, 51 (3): 205-220.

32-G. Bende, S. Kollipara, V. Kolachina, R. Saha, Development and validation of a stability indicating RP-LC method for determination of imatinib mesylate. Chromatographia, 2007, 66:859-866.

33-D. D. Ganesh, KC. Raka, BS. Honde, GS. Bhawal, PJ. Tajane, Review on flash chromatography. Int. J. Pharm. Rev. Res., 2013, 3 (1): 45- 49.

34-C. M. Nisha, A. Kumar, P. Nair et al., Molecular docking and in silico ADMET study reveals acylguanidine 7a as a potential inhibitor of $\beta$-secretase, Adv. Bio., 2016, 2016: 1- 6.

35-A. M. Vijesh, A. M. Isloor, S. Telkar, T. Arulmoli, HK. Fun, Molecular docking studies of some new imidazole derivatives for antimicrobial properties. Arab. J. Chem., 2013, 6: 197-204. 
36- Bioinformatics and Molecular Design Research Center, Seul, South Corea, PreADMET program, 2004. Available from: URL: http://preadmet.bmdrc.org.

37-Molinspiration Cheminformatics, Slovensky Grob, Slovak Republic, Molinspiration program, 2002. Available from: URL: http://www.molinspiration.com.

38-Chem Bio Office 2010, PerkinElmer Informatics, 2175 Mission College Boulevard, Santa Clara, California, USA. Available from: URL: http://www. cambridgesoft.com.

39-Molecular Operating Environment (MOE) (2019) Chemical Computing Group, Canada.

40- ICH, Stability Testing of New Drug and Products Q1A (R2), 2003, Geneva, Switzerland.

41- Ma. S. Pinheiro, G. M. Viana, B. de A. A. Vieira, Identification, characterization and in silico ADMET prediction of Roflumilast degradation products. J. Pharm. Biomed. Anal., 2017, 138: 126-133.

42- M. Kurmi, A. Sahu, D. K. Singh, I. P. Singh, Stability behaviour of antiretroviral drugs and their combinations. 8: Characterization and in-silico toxicity prediction of degradationproducts of efavirenz. J. Pharm. Biomed. Anal., 2018, 148: $170-181$.

43-A. Petruczynik, K. Wroblewski, S. Strozek, M. Waksmundzka-Hajnos, RP-HPLC analysis of acidic and basic drugs in systems with diethyl amine as eluents additive. Acta Pol. Pharm., 2016, 73 (6): 1475- 1485.

44- ICH. Q2 (R1) Validation of Analytical Procedures: Text and Methodology. ICH Harmonized Tripartite Guideline (2005).

45- Y.H. Zhao, J. Le, M.H. Abraham, A. Hersey, P.J. Eddershaw, C.N. Luscombe, D. Boutina, G. Beck, B. Sherborne, I. Cooper, J.A. Platts. Evaluation of human intestinal absorption data and subsequent derivation of a Quantitative Structure-Activity Relationship (QSAR) with the abraham descriptors. J. Pharm. Sci., 2001, 90: 749-784.

46- T.J. Hou, W. Zhang, K. Xia, X.B. Qiao, X.J. Xu. ADME Evaluation in drug discovery.5. Correlation of caco-2 permeation with simple molecular properties. J. Chem. Inf. Comput. Sci., 2004, 44: 1585-1600.

47- A.Grover, Drug Design: Principles and Applications, Jawaharlal Nehru University, New Delhi, India, Springer Singapore, 2017, 113-133.

\section{Tables}

1 Regression and analytical parameters of the developed methods and results of statistical compa ie reported method. 


\begin{tabular}{|c|c|c|c|c|c|}
\hline \multirow[t]{3}{*}{ Parameters } & \multicolumn{2}{|c|}{ RP-TLC } & \multirow{2}{*}{\multicolumn{2}{|c|}{ RP-HPLC }} & \multirow{3}{*}{$\begin{array}{c}\text { Reported method } \\
{[17]^{* *}} \\
\end{array}$} \\
\hline & & & & & \\
\hline & Colchicine & $\begin{array}{l}\text { Degradation } \\
\text { product }\end{array}$ & Colchicine & $\begin{array}{l}\text { Degradation } \\
\text { product }\end{array}$ & \\
\hline \multicolumn{6}{|l|}{ Linearity } \\
\hline Range & $\begin{array}{c}0.2-4.0 \\
\text { (ug/ band) }\end{array}$ & $\begin{array}{l}\text { 1. } 4.0 \\
\qquad(\mu \mathrm{g} / \mathrm{band})\end{array}$ & \multicolumn{2}{|c|}{$\begin{array}{c}2-40 \\
(\mu \mathrm{g} / \mathrm{mL})\end{array}$} & \\
\hline \multirow[t]{2}{*}{ Slope } & $-1198.10^{a}$ & $-521.53^{\mathrm{a}}$ & \multirow[b]{2}{*}{0.8488} & $0.0035 .00^{a}$ & \\
\hline & $10399.00^{b}$ & $5913.60^{b}$ & & $0.2027 .00^{b}$ & \\
\hline Intercept & 2197.30 & -377.64 & 0.1874 & 0.0955 & \\
\hline $\begin{array}{l}\text { elation coefficient } \\
\text { (r) }\end{array}$ & 0.9997 & 0.9998 & 0.9999 & 0.9997 & \\
\hline \multicolumn{5}{|l|}{ Precision (SD). } & \\
\hline \multirow{2}{*}{$\begin{array}{l}\text { aday precision }{ }^{\text {cd }} \\
\text { rday precision }\end{array}$} & 1.184 & 0.895 & 0.907 & 1.685 & \\
\hline & 1.735 & 1.177 & 1.097 & 1.852 & \\
\hline \multirow[t]{4}{*}{ oustness (\%RSD) } & \multicolumn{2}{|c|}{ Amount of methanol ( \pm 1\%) } & \multicolumn{2}{|c|}{ Flow rate $( \pm 0.05 \mathrm{~mL} / \mathrm{min})$} & \\
\hline & 3.77 & 1.95 & 3.02 & 2.05 & \\
\hline & \multicolumn{2}{|c|}{$\begin{array}{l}\text { Amount of diethyl amine } \\
( \pm 2 \%)\end{array}$} & \multicolumn{2}{|c|}{ Scanning wavelength $( \pm 2 \mathrm{~nm})$} & \\
\hline & 2.34 & 2.73 & 0.56 & 1.40 & \\
\hline LOD & 0.05 & 0.03 & 0.60 & 0.63 & \\
\hline LOQ & 0.16 & 0.09 & 1.85 & 1.90 & \\
\hline racy $($ mean \pm SD) & $\begin{array}{c}98.38 \pm \\
1.11\end{array}$ & $100.59 \pm 1.30$ & $\begin{array}{l}99.92 \pm \\
1.03\end{array}$ & $100.01 \pm 1.49$ & $100.31 \pm 1.74$ \\
\hline \multirow[t]{2}{*}{$\mathbf{n}$} & & & & & \multirow[t]{2}{*}{9} \\
\hline & 9 & & 9 & & \\
\hline itudent's t- test & $\begin{array}{c}1.359 \\
(2.12)^{*}\end{array}$ & & $\begin{array}{l}0.584 \\
(2.12)^{*}\end{array}$ & & \\
\hline F- value & $\begin{array}{c}2.440 \\
(3.438) * \\
\end{array}$ & & $\begin{array}{c}2.857 \\
(3.438) \\
\end{array}$ & & \\
\hline
\end{tabular}

əarity was achieved using the polynomial regression equation: $\mathrm{A}=\mathrm{aX} \mathrm{X}^{2} \mathrm{bX}+\mathrm{C}$

ficient $1 \quad \mathrm{~b}$ : Coefficient $2 \quad \mathrm{~A}=$ Peak area ratio $\quad \mathrm{X}=$ concentration $\mu \mathrm{g} / \mathrm{band}$ or $\mu \mathrm{g} / \mathrm{mL} \quad \mathrm{C}=$ intercept age of three experiments

dard deviation of 3 concentrations of each analyte (0.5, 1.5 and $2.5 \mu \mathrm{g} /$ band for RP-TLC) and (5, 20 , for RP-HPLC) on the same day.

Jard deviation of 3 concentrations of each drug (0.5, 1.5 and $2.5 \mu \mathrm{g} /$ band for RP-TLC) and (5, 20, and $\Xi$ -HPLC) on three successive days.

3.3* SD/slope $\quad \mathrm{LOQ}=10 * \mathrm{SD} /$ slope

the intercept, slope of the calibration graph)

res between parentheses represent the corresponding tabulated values of $t$ and $F$ at $p$ value of 0.05.

method [17]: HPLC method using 0.05M KH2PO4: methanol (49.5: 53, v/v) pH 5.5 with 0.5M H3PO4, flow rate $=1 \mathrm{~m}]$ ary phase of $4.6 \mathrm{~mm} \mathrm{X} 25 \mathrm{~cm}$ column containing packing L7, and the detection wavelength is $254 \mathrm{~nm}$.

2 Determination of colchicine in pharmaceutical formulation by the proposed methods and results of stc on technique. 


\begin{tabular}{|c|c|c|c|c|}
\hline \multicolumn{5}{|c|}{ RP-TLC } \\
\hline \multirow[t]{2}{*}{ Pharmaceutical formulation } & \multirow{2}{*}{$\begin{array}{c}\text { Taken } \\
\mu \mathrm{g} / \text { band }\end{array}$} & \multirow{2}{*}{$\begin{array}{c}\% \text { Found }^{\mathrm{a}} \\
\pm \mathrm{SD}\end{array}$} & \multicolumn{2}{|c|}{ Standard addition technique } \\
\hline & & & $\begin{array}{c}\text { Pure added } \\
\text { ( } \mu \mathrm{g} / \text { band) }\end{array}$ & $\%$ Found $^{b}$ \\
\hline \multirow{5}{*}{$\begin{array}{l}\text { Colchicine }{ }^{\circledR} \text { tablets } \\
\text { (B. N. 64719) } \\
\text { claimed to contain } 500 \mathrm{\mu g} / \text { colchicine/ tablet }\end{array}$} & \multirow[t]{3}{*}{1.50} & \multirow{3}{*}{$\begin{array}{c}105.38 \pm \\
1.15\end{array}$} & 1.00 & 100.00 \\
\hline & & & 1.50 & 100.00 \\
\hline & & & 2.00 & 101.50 \\
\hline & \multirow{2}{*}{\multicolumn{3}{|c|}{ Mean \pm SD }} & $100.50 \pm$ \\
\hline & & & & 0.87 \\
\hline \multicolumn{5}{|c|}{ RP-HPLC } \\
\hline \multirow[t]{2}{*}{ Pharmaceutical formulation } & \multirow{2}{*}{$\begin{array}{c}\text { Taken } \\
\mu \mathrm{g} / \mathrm{mL}\end{array}$} & \multirow{2}{*}{$\begin{array}{l}\% \text { Found }^{\mathrm{a}} \\
\quad \pm \mathrm{SD}\end{array}$} & \multicolumn{2}{|c|}{ Standard addition technique } \\
\hline & & & $\begin{array}{c}\text { Pure added } \\
(\mu \mathrm{g} / \mathrm{mL})\end{array}$ & \% Found ${ }^{b}$ \\
\hline \multirow{5}{*}{$\begin{array}{l}\text { Colchicine }{ }^{\circledR} \text { tablets } \\
\text { (B. N. 64719) } \\
\text { claimed to contain } 500 \mathrm{\mu g} / \text { colchicine/ tablet }\end{array}$} & \multirow[t]{3}{*}{15.00} & \multirow{3}{*}{$\begin{array}{c}107.16 \pm \\
2.26\end{array}$} & 10.00 & 99.56 \\
\hline & & & 15.00 & 102.90 \\
\hline & & & 20.00 & 100.63 \\
\hline & \multirow{2}{*}{\multicolumn{3}{|c|}{ Mean \pm SD }} & \\
\hline & & & & \\
\hline & & & & \\
\hline
\end{tabular}

'Average of 6 determinations.

' Average of 3 determinations.

Table 3: System suitability testing parameters of the developed methods.

\begin{tabular}{|c|c|c|c|c|}
\hline \multirow[t]{2}{*}{ Parameters } & \multicolumn{2}{|r|}{ RP-TLC } & \multicolumn{2}{|l|}{ RP-HPLC } \\
\hline & Colchicine & Degradation product & Degradation product & Colchicine \\
\hline $\mathrm{R}_{\mathrm{f}}$ or $\mathrm{t}_{\mathrm{R}}(\mathrm{min})$ & 0.60 & 0.70 & 1.97 & 2.97 \\
\hline Peak symmetry & 0.95 & 1.06 & 1.50 & 1.20 \\
\hline Capacity factor (K') & ------- & --------- & 2.94 & 4.94 \\
\hline Selectivity $(\alpha)$ & & 1.25 & 1.68 & \\
\hline Resolution $\left(\mathrm{R}_{\mathrm{s}}\right)$ & & 1.35 & 5.93 & \\
\hline Number of theoretical plates $(\mathbf{N})$ & 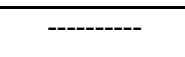 & $\begin{array}{ll}------- \\
\end{array}$ & 2759.75 & 4014.48 \\
\hline Height equivalent to theoretical plate (H) (in $\mathrm{mm}$ ) & 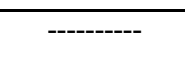 & 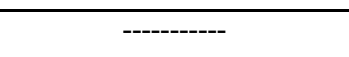 & 0.0906 & 0.0623 \\
\hline
\end{tabular}

Table 4. The values of ADME properties of the studied compounds obtained using in-silico method. 


\begin{tabular}{ccc}
\hline Molecule & Colchicine & Degradation Product \\
\hline BBB (Cbrain/Cblood) & 0.014 & 0.010 \\
\hline PPB & 65.42 & 37.33 \\
\hline HIA $\%$ & 96.90 & 97.98 \\
\hline Caco-2 $(\mathrm{nm} / \mathrm{sec})$ & 37.44 & 28.20 \\
\hline MDCK $(\mathrm{nm} / \mathrm{sec})$ & 119.15 & 168.69 \\
\hline SP $(\log$ Kp) & -3.96 & -3.97 \\
\hline GPRC & -0.08 & -0.01 \\
\hline EI & 0.05 & 0.07 \\
\hline ICM & -0.09 & 0.02 \\
\hline KI & -0.10 & 0.09 \\
\hline NRL & -0.23 & -0.13 \\
\hline PI & -0.09 & -0.15
\end{tabular}

Table 5. Compliance of the synthesized compounds to Lipinski's and Veber's rules.

\begin{tabular}{|c|c|c|c|c|c|c|}
\hline Compound & $\log \mathrm{P}(0 / w)(<5)$ & $\begin{array}{c}\text { MW } \\
(<500)\end{array}$ & $\begin{array}{l}\text { a_acc } \\
(\leq 11\end{array}$ & $\begin{array}{l}a_{-}^{a} \text { don } \\
(\leq 5)\end{array}$ & $\begin{array}{l}\text { B_rotN } \\
(\leq 10)\end{array}$ & $\begin{array}{c}\text { ASA_P } \\
(<140 \AA)\end{array}$ \\
\hline Colchicine & 2.208 & 399.44 & 6 & 1 & 6 & 187.777 \\
\hline Degradation product & 2.039 & 357.40 & 6 & 1 & 4 & 205.856 \\
\hline
\end{tabular}

$\mathrm{a}_{\text {Number of Hydrogen-bond acceptors (a_acc) }}$

bumber of Hydrogen-bond donors (a_don);

${ }^{\mathrm{C}}$ Number of rotatable bonds (B_rotN)

d Polar Surface Area (ASA_P).

Table 6. Toxicity profile of the drug and its degradate using Toxicity Prediction of preADMET protocol. 


\begin{tabular}{ccc}
\hline Molecule & Colchicine & Degradated Product \\
\hline Algae_at & 0.0798 & 0.0926 \\
\hline Ames_test & Mutagen & Mutagen \\
\hline Carcino_Mouse & Negative & Negative \\
\hline Carcino_Rat & Positive & Positive \\
\hline Daphnia_at & 0.193 & 0.230 \\
\hline hERG_inhibition & Low risk & Low risk \\
\hline Medaka_at & 0.067 & `.088 \\
\hline Minnow_at & 0.137 & 0.170 \\
\hline TA100_10RLl & Negative & Negative \\
\hline TA100_NA & Positive & Positive \\
\hline TA1535_10RLl & Negative & Negative \\
\hline TA1535_NA & Negative & Negative \\
\hline
\end{tabular}

\section{Figures}

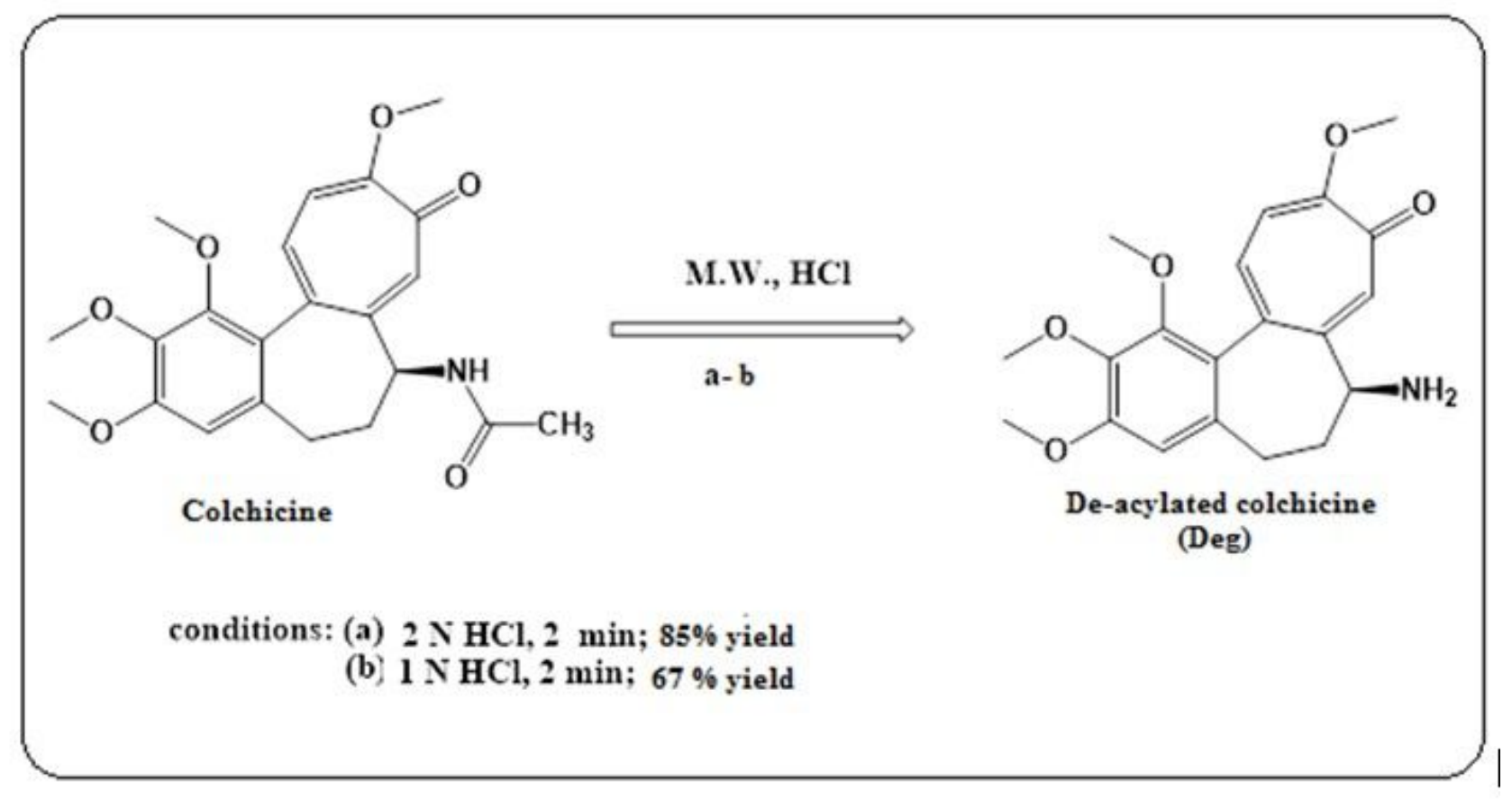

Figure 1

Schematic diagram for the hydrolytic degradation pathway of colchicine. 


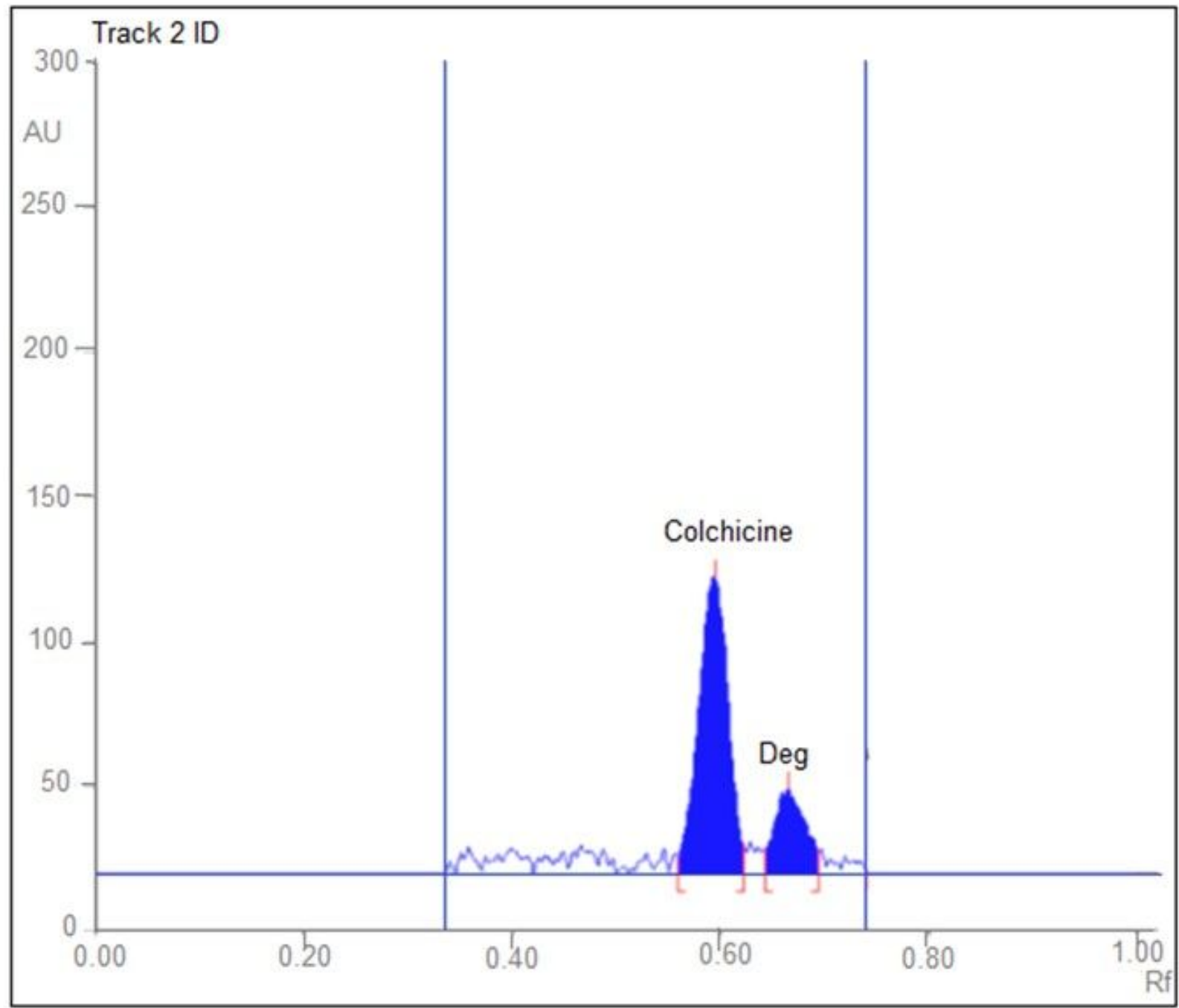

Figure 2

2D chromatogram of colchicine $(0.5 \mu \mathrm{g} /$ band $)$ and its degradation product $(0.2 \mu \mathrm{g} / \mathrm{band})$ 


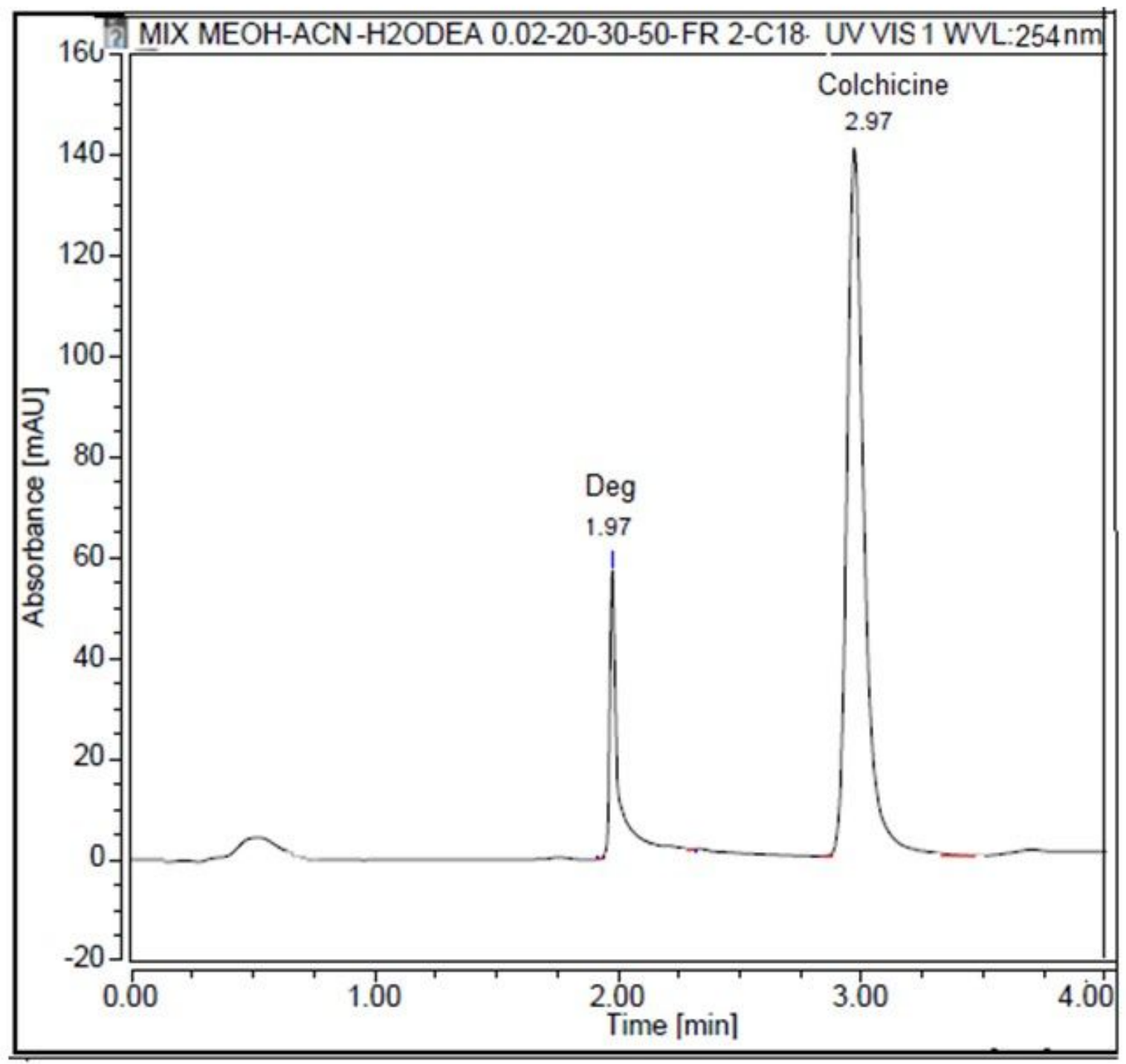

Figure 3

HPLC chromatogram of colchicine $(20 \mu \mathrm{g} / \mathrm{mL})$ and its degradation product $(10 \mu \mathrm{g} / \mathrm{mL})$ 


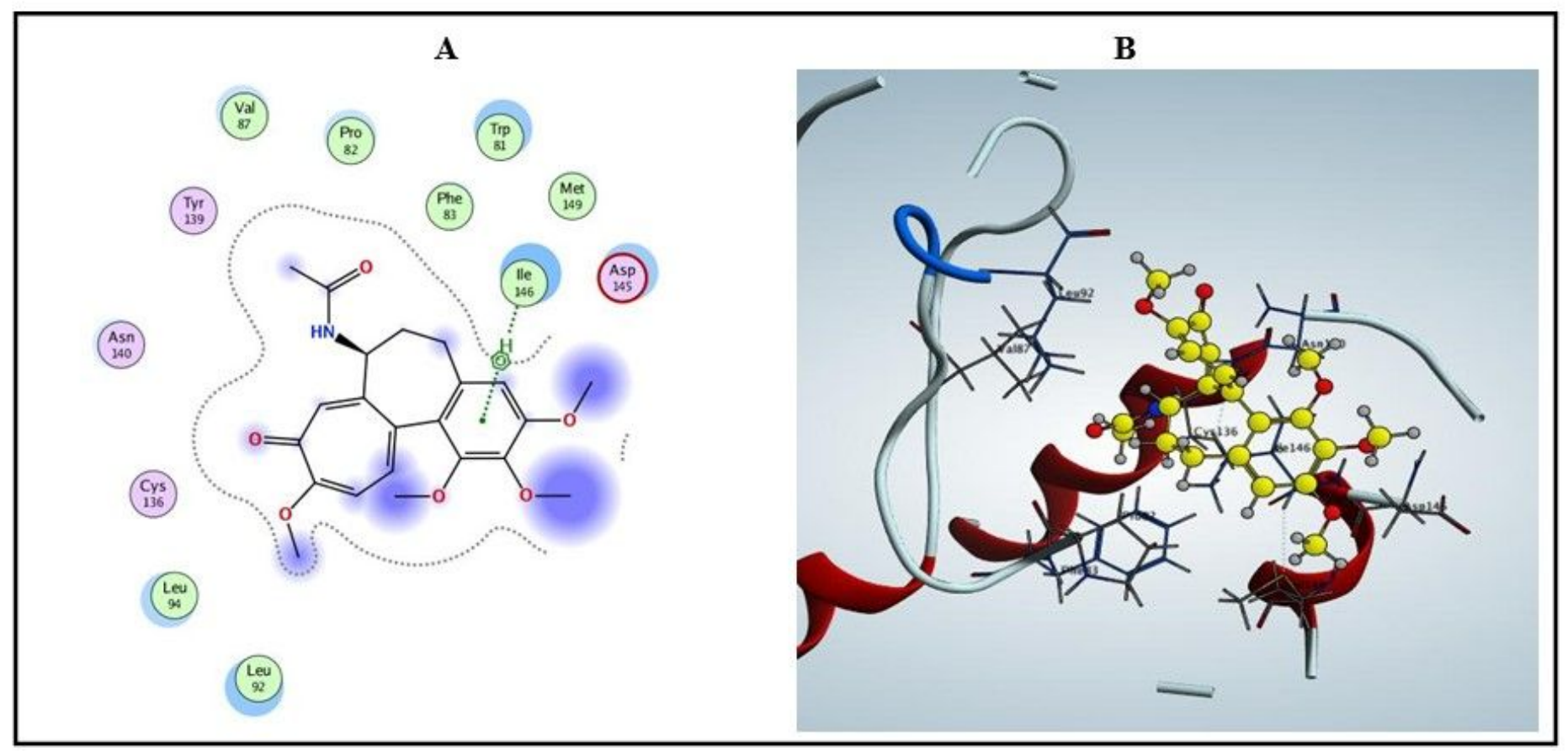

Figure 4

The 2D caption of colchicine binding to the active site of tubulin. (B) Binding pattern of the degradate colored by element, ball and stick into tubulin showing hydrogen bond interaction with Asn140 (dotted lines).

\section{Supplementary Files}

This is a list of supplementary files associated with this preprint. Click to download.

- graphicalabst.tif 